\title{
Salmonella serotypes and their antimicrobial susceptibility in apparently healthy dogs in Addis Ababa, Ethiopia
}

\author{
Bitsu Kiflu, Haile Alemayehu², Mukarim Abdurahaman³, Yohannes Negash² and Tadesse Eguale ${ }^{2^{*}}$ (D)
}

\begin{abstract}
Background: The close bond between pet animals and family members poses risk of infection with zoonotic bacterial pathogens such as Salmonella. No data is available on occurrence of Salmonella in dogs in Ethiopia. The aim of this study was therefore to determine the prevalence, serotype distribution and antimicrobial resistance of Salmonella from feces of apparently healthy dogs in Addis Ababa, Ethiopia.

Results: Of the total 360 dogs examined, 42 (11.7\%; 95\% Confidence limit of 8.5\%-15.4\%) were positive for Salmonella. Fourteen serotypes were detected and the predominant ones were S. Bronx $(n=7 ; 16.7 \%)$, S. Newport ( $n=6 ; 14.3 \%)$, followed by S. Typhimurium, S. Indiana, S. Kentucky, S. Saintpaul and S. Virchow $(n=4 ; 9.5 \%)$ each. Salmonella infection status was significantly associated with history of symptom of diarrhea during the past 60 days $(\mathrm{OR}=3.78 ; \mathrm{Cl}=1.76-8.13 ; p=0)$. Highest resistance rates were found for oxytetracycline (59.5\%), neomycin (50\%), streptomycin (38.1\%), cephalothin (33.3\%), doxycycline (30.9\%), ampicillin (30.9\%) and amoxicillin + clavulanic acid (26.2\%). Thirty eight (90.5\%) of the isolates were resistant or intermediately resistant to at least one of the 16 antimicrobials tested. Resistance to two or more antimicrobials was detected in 30 (71.4\%) of the isolates. Resistance to three or more antimicrobials was detected in 19 (45.2\%) of the isolates.

Conclusion: This study demonstrated high carriage rate of Salmonella serotypes known for causing human salmonellosis and large proportion of them were resistant to antimicrobials used in public and veterinary medicine for management of various bacterial infections, suggesting the possible risk of infection of human population in close contact with these dogs by drug resistant pathogens. Therefore, it is vital to work on raising public awareness on zoonotic canine diseases prevention measures and good hygienic practices.
\end{abstract}

Keywords: Salmonella, Serotype, Antimicrobial resistance, Dog, Zoonosis, Addis Ababa, Ethiopia

\section{Background}

Salmonellosis is an infectious disease of humans and animals caused by several serotypes of Salmonella. Salmonella is widespread in the environment and commonly found in farm effluents, human sewage and in any material subjected to fecal contamination [1]. Salmonella in animals are of major concern, because animals can serve as latent carriers of Salmonella serotypes and shed the organism into the environment without any apparent clinical signs posing risk of human infection [2]. Dogs are one of the important asymptomatic

\footnotetext{
* Correspondence: tadesse.eguale@aau.edu.et

${ }^{2}$ Aklilu Lemma Institute of Pathobiology, Addis Ababa University, P.O. Box

1176, Addis Ababa, Ethiopia

Full list of author information is available at the end of the article
}

carriers of Salmonella, as they can harbour large bacterial load in the intestines and mesenteric lymph nodes which can be shed in their feces [3]. This could be of significant importance to public health as dogs have close contact with family members in households.

Antimicrobial resistant Salmonella and other zoonotic pathogens originating from companion animals have a great public health importance. The majority of studies on antimicrobial resistance in Salmonella focused on food animals and farm environments, since food animals are believed to be the major sources of resistant strains of non-typhoidal Salmonella. However, a few studies reported antimicrobial resistant Salmonella isolates, including multidrug resistant (MDR) ones from dogs 
and other companion animals in different parts of the world [4-6].

In Ethiopia, no data is available on occurrence of zoonotic bacterial pathogens in dogs and possible risk of human infection with Salmonella from dogs. Majority of previous work focused mainly on food animals and food items [7, 8]. However, there is an increasing trend of keeping dogs in urban areas and demand for general veterinary services for dogs is also increasing [9]. The objectives of this study were therefore to investigate the prevalence, serotype distribution and antimicrobial susceptibility of Salmonella isolates from apparently healthy dogs in Addis Ababa, Ethiopia. In addition, various factors were also examined for the possible association of Salmonella occurrence in dogs.

\section{Methods}

\section{Study area and study animals}

The study was conducted from January to October, 2015 in Addis Ababa, which is the capital city and administration center for the Federal Democratic Republic of Ethiopia. Among ten sub-cities, four sub-cities namely, Gulele, Arada, Kirkos and Yeka were randomly selected. A total of 360 dogs were involved in this study. Those brought to veterinary clinics for anti-rabies vaccination ( $n=264)$ were sampled. In addition, dogs $(n=96)$ were also sampled through door to door visit from households. Apparently healthy dogs of all age groups and both sexes were included in the study. Sick dogs and/or dogs treated recently with antimicrobials were not included in the study.

\section{Sample and data collection}

Rectal swab samples were collected with sterile cotton swab by rotating the swab inside the rectum of the dog and the swab was placed into screw caped test tubes containing $10 \mathrm{ml}$ of sterile buffered peptone water (BPW) (Becton Dickinson, France). The test tubes were properly labeled and transported in ice box to Microbiology Laboratory of Aklilu Lemma Institute of Pathobiology, Addis Ababa University within 3-4 h of collection.

During sample collection, data was also collected from 252 households using a questionnaire that focused on assessing the possible risk factors of Salmonella infection. Possible risk factors considered for the presence of Salmonella including: age, sex, history of diarrhea during the last 2 months, purpose of dog ownership, type of food and source of food/meat provided to dog were among the questions included in the questionnaire.

\section{Salmonella isolation and identification}

Isolation and identification of Salmonella was conducted as described previously [7]. Briefly, fecal swabs in buffered peptone water (BPW) pre-enrichment broth were homogenized using vortex mixer for $30 \mathrm{~s}$ and incubated at $37{ }^{\circ} \mathrm{C}$ for $24 \mathrm{~h}$. A $100 \mu \mathrm{l}$ pre-enriched suspension was added into $9.9 \mathrm{ml}$ of Rappaport-Vassiliadis enrichment Broth (RVB) (Oxoid, USA) and incubated at $42{ }^{\circ} \mathrm{C}$ for $24 \mathrm{~h}$. At the same time, $1 \mathrm{ml}$ of suspension was also transferred to $9 \mathrm{ml}$ of Tetrathionate broth (TTB) (Oxoid, USA) and incubated for $24 \mathrm{~h}$ at $37{ }^{\circ} \mathrm{C}$. It was then streaked from both RVB and TTB to Xylose Lysine Tergitol 4 (XLT-4) (Oxoid, USA) and Brilliant Green Agar (BGA) (Difco Becton Dickinson, USA) selective media and the plates were then incubated at $37{ }^{\circ} \mathrm{C}$ for $24 \mathrm{~h}$. XLT- 4 plates were incubated for additional $24 \mathrm{~h}$ and second reading was conducted at $48 \mathrm{~h}$. Presumptive Salmonella colonies were further investigated biochemically using Triple Sugar Iron agar, Urea, Citrate and Lysine Iron Agar slants. Those colonies with typical Salmonella biochemical properties were then further confirmed by genus specific polymerase chain reaction (PCR) [10]. Reference strain of $S$. Typhimurium (ATCC 14028) was used as a positive control during biochemical analysis and PCR. Confirmed Salmonella isolates were stored at $-80{ }^{\circ} \mathrm{C}$ in $20 \%$ glycerol until further testing.

\section{Salmonella serotyping and phage typing}

Salmonella isolates were serotyped and phage-typed at the Public Health Agency of Canada, World Organization for Animal Health (OIÉ) Reference Laboratory for Salmonellosis, Guelph, Ontario, Canada. Briefly, the somatic $(\mathrm{O})$ antigens were determined by slide agglutination tests [11] and flagellar antigens were determined using a microplate agglutination technique [12]. The antigenic formulae of Grimont and Weill [13] were used to identify and assign the serotypes of the isolates. Phage typing of $S$. Typhimurium isolates was performed according to Anderson et al. [14] with reference phages obtained from the Public Health England, Gastrointestinal Bacteria Reference Unit, Colindale, England and the Public Health Agency of Canada, National Laboratory for Enteric Pathogens, Winnipeg, Canada. Salmonella isolates that reacted with the phages but did not conform to any recognized phage type were designated atypical (AT).

\section{Antimicrobial susceptibility testing}

Susceptibility of the isolates to 16 antimicrobials was determined using the disk diffusion method according to the guidelines of the Clinical and Laboratory Standards Institute [15]. Briefly, frozen isolates were subcultured on tryptic soy agar (Becton, Dickinson and Company, USA) from which 3 to 4 pure colonies were inoculated to a tube containing $5 \mathrm{ml}$ of tryptic soy broth (TSB) (Becton, Dickinson and Company, USA) and mixed gently using sterile inoculating loop. It was then incubated at $37^{\circ} \mathrm{C}$ for $4-5 \mathrm{~h}$. The turbidity of the suspension was then adjusted to the optical density of a McFarland unit 
of 0.5 using sterile saline to standardize the inoculum size. Sterile cotton swab was dipped and rotated several times and pressed firmly on the inside wall of the tube above the fluid level to remove excess inoculum. It was then inoculated to Mueller Hinton Agar plate (Oxoid, Ltd) by streaking the swab over the entire surface of the plate. The inoculated plates were left at room temperature to dry for 5-10 $\mathrm{min}$ and antimicrobial discs were dispensed by pressing on the plate with sterile forceps and the plates were inverted and incubated at $37{ }^{\circ} \mathrm{C}$ overnight. Diameters of the zone of inhibition were measured to the nearest millimeter using a plastic transparent ruler. The interpretation of the categories of susceptible, intermediate or resistant was based on the CLSI guidelines [15]. The cut off points used for the interpretation is shown in Table 1. For the purpose of analysis, all readings classified as intermediate were considered as resistant unless indicated. Reference strain of Escherichia coli ATCC 25922 was used as a quality control. The list of antimicrobial discs (Sensi-Discs, Becton, Dickinson and Company, Loveton, USA) used in the study and their strength is shown in Table 1.

\section{Statistical analysis}

The data were computed by using statistical package for social sciences (SPSS version 20.0). The association between Salmonella occurrence and pre-specified categorical factors were compared using person's $x^{2}$ test. The point prevalence was calculated as the number of infected individuals divided by the number of individual's sampled $\times 100$. A $p$ - value $<0.05$ was reported as statistically significant.

\section{Results}

Occurrence of Salmonella in dogs

Of the total 360 dogs examined, 42 (11.67\%; 95\% confidence limit of $8.5 \%-15.4 \%$ ) were positive for Salmonella. There was no significant difference in prevalence of Salmonella among dogs from different sub-cities, purpose for which the dogs were kept and type and source of food/meat provided to dogs. Similarly, there was no significant difference in Salmonella carriage among age groups and sex $(p>0.05)$ (Table 2). Isolation of Salmonella was observed to be more common among dogs who had diarrhea within the past 2 months compared to those with no history of diarrhea $(\mathrm{OR}=3.78$, 95\% CI = 1.76-8.13) (Table 3).

\section{Salmonella serotype distribution}

Overall, 14 different Salmonella serotypes were recovered, the predominant serotypes were $S$. Bronx ( $n=7 ; 16.7 \%), S$. Newport ( $n=6 ; 14.3 \%), S$. Typhimurium $(n=4 ; 9.5 \%), S$. Indiana $(n=4 ; 9.5 \%), S$. Kentucky $(n=4 ; 9.5 \%), S$. Saintpaul $(n=4 ; 9.5 \%)$ and $S$. Virchow $(n=4 ; 9.5 \%)$. Other serotypes such as $S$. Anatum $(n=2), S$. Haifa $(n=2), S$. Braenderup $(n=1), S$. Chailey $(n=1), S$. Minnesota $(n=1), S$. Muenchen $(n=1)$ and $S$. Tarshyne $(n=1)$ were also identified (Table 4). To our knowledge, S. Bronx, $S$. Chailey, $S$. Indiana, $S$. Minnesota and $S$. Tarshyne are reported for the first time in Ethiopia. Phagetyping of the

Table 1 List of antimicrobial discs used in the study, their strength and zone diameter interpretive cut off points in mm

\begin{tabular}{|c|c|c|c|c|}
\hline Disk & Disc strength in $\mu \mathrm{g}$ & $\begin{array}{l}\text { Resistant } \\
\leq(\mathrm{mm})\end{array}$ & $\begin{array}{l}\text { Intermediate } \\
(\mathrm{mm})\end{array}$ & $\begin{array}{l}\text { Susceptible } \\
\geq(\mathrm{mm})\end{array}$ \\
\hline Amikacin & 30 & 14 & $15-16$ & 17 \\
\hline Amoxicillin + clavulanic acid & $20 / 10$ & 13 & $14-17$ & 18 \\
\hline Ampicillin & 10 & 13 & $14-16$ & 17 \\
\hline Cefoxitin & 30 & 14 & $15-17$ & 18 \\
\hline Ceftriaxone & 30 & 19 & $20-22$ & 23 \\
\hline Cephalothin & 30 & 14 & $15-17$ & 18 \\
\hline Chloramphenicol & 30 & 12 & $13-17$ & 18 \\
\hline Ciprofloxacin & 5 & 20 & $21-30$ & 31 \\
\hline Doxycycline & 30 & 10 & $11-13$ & 14 \\
\hline Gentamicin & 10 & 12 & $13-14$ & 15 \\
\hline Kanamycin & 30 & 13 & $14-17$ & 18 \\
\hline Nalidixic acid & 30 & 13 & $14-18$ & 19 \\
\hline Neomycin & 30 & 12 & $13-16$ & 17 \\
\hline Oxytetracycline & 30 & 11 & $12-14$ & 15 \\
\hline Streptomycin & 10 & 11 & $12-14$ & 15 \\
\hline Sulfamethoxazole and Trimethoprim & 23.75 and 1.25 & 10 & $11-15$ & 16 \\
\hline
\end{tabular}


Table 2 Frequency of Salmonella carriage among apparently healthy dogs with respect to selected factors

\begin{tabular}{|c|c|c|c|c|}
\hline Variables categories & & Number examined & No. positive (\%) & $x^{2}(p$-value $)$ \\
\hline \multirow[t]{4}{*}{ Sub-cities } & Gulele & 137 & $16(11.7)$ & $2.1(0.6)$ \\
\hline & Arada & 78 & $7(9)$ & \\
\hline & Kirkos & 83 & $13(15.7)$ & \\
\hline & Yeka & 62 & $6(9.7)$ & \\
\hline \multirow[t]{2}{*}{ Sex } & Male & 291 & $35(12.0)$ & $0.2(0.7)$ \\
\hline & Female & 69 & $7(10.1)$ & \\
\hline \multirow[t]{5}{*}{ Age } & Puppy (<6 month) & 73 & $11(15.0)$ & $4.6(0.3)$ \\
\hline & $>6$ months -2 yrs & 84 & $9(10.7)$ & \\
\hline & $>2$ yrs. $-6 y r s$ & 137 & $16(11.7)$ & \\
\hline & $>6 \mathrm{yrs}$. to $10 \mathrm{yrs}$ & 46 & $2(4.3)$ & \\
\hline & Over 10 yrs & 20 & $4(20)$ & \\
\hline \multirow[t]{3}{*}{ Purpose of dog ownership } & Guard & 130 & $19(14.7)$ & $2.9(0.2)$ \\
\hline & Hobby & 86 & $6(6.9)$ & \\
\hline & Guard + hobby & 144 & $17(11.8)$ & \\
\hline Overall & & 360 & $42(11.7)$ & \\
\hline
\end{tabular}

4. S. Typhimurium showed that two of the isolates were phage type 74 while the other two were atypical.

\section{Antimicrobial susceptibility of Salmonella isolates}

Frequency of isolates resistant or intermediately resistant to various antimicrobials is shown in Table 4. High resistance rate was recorded among isolates to oxytetracycline 25(59.5\%), neomycin 21 (50\%), streptomycin 16 (38.1\%), cephalothin 14 (33.3\%), doxycycline 13 (30.9\%), ampicillin 13 (30.9\%), and amoxicillin + clavulanic acid $11(26.2 \%)$. All isolates were susceptible to ciprofloxacin and amikacin. Of the 42 Salmonella isolates, 38 (90.5\%) were resistant to one or more of the antimicrobials tested. Resistance to two or more antimicrobials was detected in $30(71.4 \%)$ of the isolates. Resistance to three or more antimicrobials was detected in 19 (45.2\%) of the isolates. Resistance to five or more antimicrobials was detected in $10(23.8 \%)$ of the isolates whereas $4(9.5 \%)$ isolates were MDR to eight or more antimicrobials.

Different serotypes appeared to exhibit disparity in their susceptibility to some of the antimicrobials tested. For instance all $S$. Newport isolates were resistant to three or more antimicrobials. Likewise, 3 of the $4 \mathrm{~S}$. Saintpaul isolates were resistant to five or more antimicrobials. On the other hand, strains belonging to $S$. Virchow, S. Typhimurium and $S$. Kentucky were resistant to relatively less number of antimicrobials (Table 5).

\section{Discussion}

Overall Salmonella prevalence of $11.7 \%$ in the current study is in line with the study conducted in Thailand in dogs which reported $13.2 \%$ of Salmonella carriage [16].

Table 3 Association of various factors with carriage of Salmonella among dogs in Addis Ababa

\begin{tabular}{|c|c|c|c|c|c|}
\hline Variables & Categorical parameter & No. sampled & No. positive for Salmonella (\%) & $\mathrm{OR}(95 \% \mathrm{Cl})$ & $\overline{x^{2}(p \text {-value })}$ \\
\hline \multirow[t]{2}{*}{ Diarrhea during the last months } & Yes & 62 & $16(25.8)$ & $3.8(1.8-8.1)$ & $(0.0)$ \\
\hline & No & 190 & $16(8.4)$ & & \\
\hline \multirow[t]{4}{*}{ Type of food provided to the dog } & Meat & 21 & $1(4.8)$ & - & $2.9(0.3)$ \\
\hline & Table scraps & 17 & $4(23.5)$ & & \\
\hline & Meat + table scraps & 211 & $27(12.8)$ & & \\
\hline & Commercial pet food & 3 & 0 & & \\
\hline \multirow[t]{3}{*}{ Source of food/meat for dogs } & Local unlicensed markets & 198 & $24(12.1)$ & - & $0.9(0.6)$ \\
\hline & Licensed butchers & 51 & $8(15.7)$ & & \\
\hline & Supermarkets & 3 & 0 & & \\
\hline Overall & & 252 & 32 & & \\
\hline
\end{tabular}




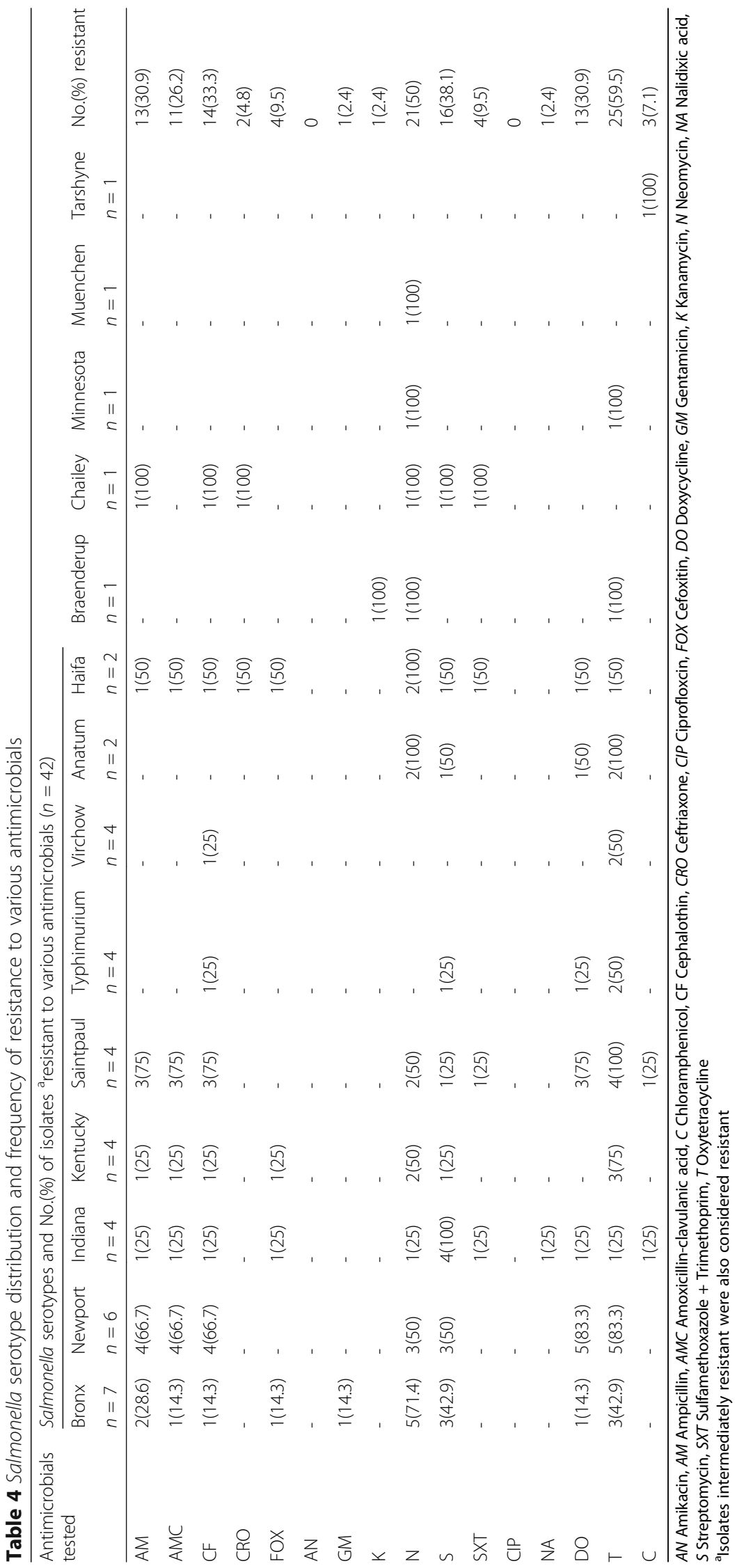


Table 5 Antimicrobial resistance pattern of Salmonella serotypes isolated from dogs

\begin{tabular}{|c|c|c|c|c|}
\hline \multirow[t]{2}{*}{ Number } & \multirow[t]{2}{*}{ Serotypes } & \multirow[t]{2}{*}{ No. } & \multicolumn{2}{|c|}{ Resistance pattern } \\
\hline & & & Intermediate & Resistant \\
\hline 1 & Anatum & 1 & $\mathrm{~N}, \mathrm{~T}$ & - \\
\hline 2 & Anatum & 1 & N & $\mathrm{DO}, \mathrm{S}, \mathrm{T}$ \\
\hline 3 & Braenderup & 1 & $\mathrm{~K}, \mathrm{~N}, \mathrm{~T}$ & - \\
\hline 4 & Bronx & 1 & $N, T$ & - \\
\hline 5 & Bronx & 1 & T & - \\
\hline 6 & Bronx & 1 & $A M C, D O, N, S$ & $A M, C F, F O X, G M$ \\
\hline 7 & Bronx & 1 & $N, T$ & AM \\
\hline 8 & Bronx & 2 & $N, S$ & - \\
\hline 9 & Bronx & 1 & - & - \\
\hline 10 & Chailey & 1 & $\mathrm{~N}, \mathrm{~S}$ & $A M, C F, C R O, S X T$ \\
\hline 11 & Haifa & 1 & N & $\mathrm{DO}, \mathrm{T}$ \\
\hline 12 & Haifa & 1 & $C R O, N, A M$ & AMC, CF, FOX, S, SXT \\
\hline 13 & Indiana & 1 & $\mathrm{~N}, \mathrm{~S}$ & - \\
\hline 14 & Indiana & 2 & S & - \\
\hline 15 & Indiana & 1 & $\mathrm{DO}, \mathrm{NA}, \mathrm{T}$ & AM, AMC, C, CF, FOX, S, SXT \\
\hline 16 & Kentucky & 1 & - & $\mathrm{AM}, \mathrm{AMC}, \mathrm{CF}, \mathrm{FOX}$ \\
\hline 17 & Kentucky & 1 & $S, T$ & - \\
\hline 18 & Kentucky & 2 & $N, T$ & - \\
\hline 19 & Minnesota & 1 & $\mathrm{~N}, \mathrm{~T}$ & - \\
\hline 20 & Muenchen & 1 & N & - \\
\hline 21 & Newport & 1 & $C F, N$ & $A M, A M C, D O, T$ \\
\hline 22 & Newport & 1 & N & $\mathrm{AM}, \mathrm{AMC}, \mathrm{CF}$ \\
\hline 23 & Newport & 2 & - & $\mathrm{DO}, \mathrm{S}, \mathrm{T}$ \\
\hline 24 & Newport & 1 & AM, N & $\mathrm{AMC}, \mathrm{CF}, \mathrm{DO}, \mathrm{S}, \mathrm{T}$ \\
\hline 25 & Newport & 1 & DO & $\mathrm{AM}, \mathrm{AMC}, \mathrm{CF}, \mathrm{T}$ \\
\hline 26 & Saintpaul & 1 & CF & $A M, A M C, D O, T$ \\
\hline 27 & Saintpaul & 1 & N & $\mathrm{AM}, \mathrm{AMC}, \mathrm{CF}, \mathrm{DO}, \mathrm{T}$ \\
\hline 28 & Saintpaul & 1 & $C F, S$ & AM, AMC, C, DO, SXT, T \\
\hline 29 & Saintpaul & 1 & $\mathrm{~T}, \mathrm{~N}$ & - \\
\hline 30 & Tarshyne & 1 & - & $C$ \\
\hline 31 & Typhimurium Pt 74 & 1 & - & - \\
\hline 32 & Typhimurium Pt 74 & 1 & $C F, S, T$ & - \\
\hline 33 & Typhimurium At & 1 & - & - \\
\hline 34 & Typhimurium At & 1 & - & $\mathrm{DO}, \mathrm{T}$ \\
\hline 35 & Virchow & 2 & T & - \\
\hline 36 & Virchow & 1 & - & - \\
\hline 37 & Virchow & 1 & CF & - \\
\hline
\end{tabular}

Similarly, prevalence in dogs in Iran (13.2\%), was comparable to the current finding [2]. However, studies in some developed countries showed much lower rates of Salmonella carriage compared to the present finding, for example, $0 \%$ in Canada [17]; $0.2 \%$ in UK [18], $1 \%$ in Turkey [19], and $2.3 \%$ in Colorado, USA [20]. The possible reason for the high prevalence of Salmonella in the current study and other previous studies compared to the ones conducted in developed countries could be due to differences in pet sanitary practices, feeding habit, difference in public awareness about dog zoonosis and socioeconomic status of the owners. Dog owners in 
developed countries are aware of the importance of hygiene and make use of the available veterinary care for their animals [21]. In addition, some factors such as difference in season of study, geographical areas and isolation methods employed might have also accounted for the observed difference [22]. In the current study, we used rectal swab samples instead of collection of larger volume of fecal samples which could have probably underestimated the true prevalence.

The association between Salmonella carriage and history of diarrhea during the past 2 months could presumably be due to Salmonella being one of the causes of clinical disease manifested by diarrhea in this dog population. In line to our finding, a study conducted in Texas, USA reported an association between diarrhea and positive Salmonella status in dogs [23]. Clinical salmonellosis is rare in dogs, but clinical signs including diarrhea, fever, anorexia, and abdominal pain are not uncommon [24].

A high degree of serotype diversity was observed among Salmonella isolates in the present study of which $S$. Bronx, $S$. Chailey, $S$. Indiana, $S$. Minnesota and $S$. Tarshyne had never been reported from Ethiopia. In related studies conducted in other countries, $S$. Newport and $S$. Typhimurium were reported from dogs [25-27] and pet food [28]. Lefebvre et al. [29] reported that $S$. Kentucky and $S$. Typhimurium were the most common serotypes recovered from dogs in Canada. Leonard et al. [30] also reported S. Kentucky as the second most dominant serotype isolated from dogs in Ontario, Canada. Some of the Salmonella serotypes isolated in the current study such as $S$. Bronx, $S$. Chailey and $S$. Tarshyne had not been previously reported from dogs. However, they were reported from other sources including humans in other countries. S. Chailey was isolated from human patients in Korea and New Zeland [31, 32], $S$. Tarshyne from antelope, ostrich and caracal [33]. S. Bronx, the predominant serotype in the current study was first isolated from diarrheic human patient in 1955 in USA [34] and our literature search showed no other report from any other source.

Some of the serotypes reported in this study were previously isolated from animals and animal products in the country. For instance: $S$. Newport, S.Typhimurium, $S$. Kentucky, S. Saintpaul, S. Virchow [7, 8, 35]. Moreover, majority of the serotypes identified in the current study such as $S$. Kentucky, $S$. Typhimurium, $S$. Virchow, $S$. Saintpaul were also isolated from diarrheic human patients in Addis Ababa in our recent study [36]. In this study, it was found that stool samples of $7.2 \%$ of the diarrheic human patients attending primary health centers in Addis Ababa were positive for Salmonella. The co-occurrence of similar serotypes in companion animals, food animals and humans suggests the circulation of these serotypes among various hosts in the study area.
Majority of the isolates in the current study were resistant or intermediately resistant to at least one antimicrobial and the prevalence of resistance was high to oxytetracycline, neomycin and streptomycin. Similarly, previous antimicrobial resistance studies on canine Salmonella in Trinidad [22] and Taiwan [37] reported higher levels of resistance. In contrast, a study conducted in Nigeria [38] in Salmonella isolates recovered from dogs demonstrated lower resistance rate to most of antimicrobials tested. The reason for difference in antimicrobial resistance profile between studies could be due to difference in serotypes involved and differences in the antimicrobial usage in humans, food animals as well as pets in respective study areas. The one possible reason for higher antimicrobial resistance in our finding could be, as feeding dogs with raw meat is common practice in Addis Ababa, there is a high chance of exposure to antimicrobial resistant Salmonella from different animal products used as pet food. High resistance rate to oxytetracycline and streptomycin in this study could be due to the fact that these drugs are the most commonly used antimicrobials in veterinary medicine in the country $[7,39]$, and as the majority of the dog owners in Addis Ababa feed raw animal products to their dogs [40], chance of being infected with resistant Salmonella from these raw animal products is very high. Previous work showed $71.3 \%$ of beef obtained from cattle slaughtered in central Ethiopia contained oxytetracycline residue [41]. Uncooked meat products such as head of cattle, sheep and goats, legs of slaughtered animals are the common food given for dogs in Addis Ababa.

$S$. Newport and S. Saintpaul showed high rate of resistance to many antimicorbials tested. This may be due to the fact that these serotypes were among the commonly isolated Salmonella serotypes from animal products in Ethiopia [42] and they might had possibly been subjected to various antimicrobials which might have rendered them to develop resistace and eventually got access to dogs through food.

\section{Conclusion}

This study showed high carriage rate of Salmonella serotypes commonly known for causing human salmonellosis and some of these isolates were resistant to antimicrobials used both in human and veterinary medicine for management of various bacterial infections, suggesting the possible risk of MDR Salmonella infection of human population in close contact with these dogs. Therefore, it is important to raise public awareness on zoonotic canine diseases prevention measures and good hygienic practices. Feeding dogs with cooked meat products, provision of clean water and improving hygiene of pet husbandry practices is therefore essential to prevent further spread of Salmonella and other foodborne zoonotic pathogens in dogs and people in close contact with dogs. 


\section{Abbreviations}

BGA: Brilliant Green Agar; BPW: Buffered peptone water; MDR: Multi-drug resistance; RVB: Rappaport-Vassiliadis Broth; TTB: Tetrathionate broth; XLT-4: Xylose Lysine Tergitol 4

\section{Acknowledgments}

We would like to thank animal health professionals at various veterinary clinics in Addis Ababa and dog owners for their cooperation during sample collection. We are grateful to Dr. Roger P. Johnson, Dr. Linda Cole, Shaun Kernaghan, Ketna Mistry, Ann Perets and Betty Wilkie of the Public Health Agency of Canada, National Microbiology Laboratory at Guelph for serotyping and phagetyping of the Salmonella isolates.

\section{Funding}

This study was partly supported by Jimma University and Aklilu Lemma Institute of Pathobiology, Addis Ababa University.

\section{Availability of data and materials}

All the data supporting the findings are presented in the manuscript.

\section{Authors' contributions}

TE was involved in conception of the study and preparation of the manuscript. BK was involved in sample collection, laboratory investigation and preparation of the draft manuscript. HA and YN participated in laboratory work. MA participated in preparation of the manuscript and data analysis. All authors read and approved the final manuscript.

\section{Competing interests}

The authors declare that they have no competing interests.

\section{Consent for publication}

Not applicable.

\section{Ethics approval and consent to participate}

Study was approved by Research and Publication Committee of College of Agriculture and Veterinary Medicine, Jimma University. Informed oral consent was obtained from the dog owners at the time of sample collection.

\section{Publisher's Note}

Springer Nature remains neutral with regard to jurisdictional claims in published maps and institutional affiliations.

\section{Author details}

${ }^{1}$ Ministry of Livestock and Fisheries, P.O. Box 170042, Addis Ababa, Ethiopia. ${ }^{2}$ Aklilu Lemma Institute of Pathobiology, Addis Ababa University, P.O. Box 1176, Addis Ababa, Ethiopia. ${ }^{3}$ College of Agriculture and Veterinary Medicine, Jimma University, P.O.Box 307, Jimma, Ethiopia.

Received: 4 January 2017 Accepted: 11 May 2017 Published online: 19 May 2017

\section{References}

1. OIE. Report of the meeting of the OIE ad hoc group on Salmonellosis. May 2010 ed. Paris: World Organisation for Animal Health; 2010

2. Salehi T, Badouei M, Madadgar O, Ghiasi S, Tamai I. Shepherd dogs as a common source for salmonella enterica serovar reading in Garmsar, Iran. Turk J Vet Anim Sci. 2013:37:102-5.

3. Hoelzer K, Moreno Switt Al, Wiedmann M. Animal contact as a source of human non-typhoidal salmonellosis. Vet Res. 2011:42:34.

4. Guardabassi L, Schwarz S, Lloyd DH. Pet animals as reservoirs of antimicrobial-resistant bacteria. J Antimicrob Chemother. 2004;54(2):321-32.

5. Lloyd DH. Reservoirs of antimicrobial resistance in pet animals. Clin Infect Dis. 2007:45(Suppl 2):S148-52

6. Umber JK, Bender JB. Pets and antimicrobial resistance. Vet Clin North Am Small Anim Pract. 2009;39(2):279-92

7. Eguale T, Engidawork E, Gebreyes AW, Asrat D, Alemayehu H, Medhin G, Johnson RP, Gunn JS. Fecal prevalence, serotype distribution and antimicrobial resistance of salmonellae in dairy cattle in central Ethiopia. BMC Microbiol. 2016;16(1):1-11.
8. Zewdu E, Cornelius P. Antimicrobial resistance pattern of salmonella serotypes isolated from food items and personnel in Addis Ababa, Ethiopia. Trop Anim Health Prod. 2009:41(2):241-9.

9. Atsbaha G, Hussien D, Cruz Cruz R. Assessment of major health problems of dogs in Mekelle City, Ethiopia. Global Veterinaria. 2014;12(2):176-80.

10. Cohen ND, Neibergs HL, McGruder ED, Whitford HW, Behle RW, Ray PM, Hargis BM. Genus-specific detection of salmonellae using the polymerase chain reaction (PCR). J Vet Diagn Investig. 1993;5(3):368-71.

11. Ewing. Serological Identificaiton of Salmonella. 1986.

12. Shipp CR, Rowe B. A mechanised microtechnique for salmonella serotyping. I Clin Pathol. 1980;33(6):595-7.

13. Grimont P, Weill F-X. Antigenic formulas of salmonella serotypes. 9th ed. France: WHO Collaborating Centre for Reference and Research on Salmonella; 2007.

14. Anderson ES, Ward LR, Saxe MJ, de Sa JD. Bacteriophage-typing designations of salmonella typhimurium. J Hyg (Lond). 1977:78(2):297-300.

15. CLSI: Performance standards for antimicrobial susceptibility testing; twenty-third informational SupplementM100-S23. Vol. 33; 2013.

16. Polpakdee A, Angkititrakul S, Suksawat F, Sparagano O, Kanistanon K. Epidemiology and antimicrobial resistance of salmonella sp. isolated from dogs and cats in northeastern Thailand. J Anim Vet Adv. 2012;11(5):618-21.

17. Murphy C, Reid-Smith RJ, Prescott JF, Bonnett BN, Poppe C, Boerlin P, Weese JS, Janecko N, McEwen SA. Occurrence of antimicrobial resistant bacteria in healthy dogs and cats presented to private veterinary hospitals in southern Ontario: a preliminary study. Can Vet J. 2009;50(10):1047-53.

18. Lowden P, Wallis C, Gee N, Hilton A. Investigating the prevalence of salmonella in dogs within the midlands region of the United Kingdom. BMC Vet Res. 2015;11:239.

19. Bagcigil AF, Ikiz S, Dokuzeylu B, Basaran B, Or E, Ozgur NY. Fecal shedding of salmonella spp. in dogs. J Vet Med Sci. 2007;69(7):775-7.

20. Hackett T, Lappin MR. Prevalence of enteric pathogens in dogs of north-central Colorado. J Am Anim Hosp Assoc. 2003;39(1):52-6.

21. Stull JW, Peregrine AS, Sargeant JM, Weese JS. Pet husbandry and infection control practices related to zoonotic disease risks in Ontario, Canada. BMC Public Health. 2013:13:520.

22. Seepersadsingh N, Adesiyun AA, Seebaransingh R. Prevalence and antimicrobial resistance of salmonella spp. in non-diarrhoeic dogs in Trinidad. J Vet Med B Infect Dis Vet Public Health. 2004;51 (7):337-42.

23. Leahy AM, Cummings KJ, Rodriguez-Rivera LD, Rankin SC, Hamer SA. Evaluation of faecal salmonella shedding among dogs at seven animal shelters across Texas. Zoonoses Public Health. 2016:63(7):515-21.

24. Marks SL, Kather EJ. Bacterial-associated diarrhea in the dog: a critical appraisal. Vet Clin North Am Small Anim Pract. 2003;33(5):1029-60.

25. Morley PS, Strohmeyer RA, Tankson JD, Hyatt DR, Dargatz DA, Fedorka-Cray PJ. Evaluation of the association between feeding raw meat and salmonella enterica infections at a greyhound breeding facility. J Am Vet Med Assoc. 2006;228(10):1524-32.

26. McKenzie E, Riehl J, Banse H, Kass PH, Nelson S Jr, Marks SL. Prevalence of diarrhea and enteropathogens in racing sled dogs. J Vet Intern Med. 2010:24(1):97-103

27. Ojo O, Ernest O, Adetosoye A. Salmonella Typhimurium infection in diarrhoeic and non-diarrhoiec dogs in Ibadan, Nigeria. Veterinarski Arhiv. 2009;79(4):371-7.

28. CDC. Human salmonellosis associated with animal-derived pet treats-United States and Canada, 2005, Centers for Disease Control and Prevention. MMWR Morb Mortal Wkly Rep. 2006;55(25):702-5.

29. Lefebvre SL, Reid-Smith R, Boerlin P, Weese JS. Evaluation of the risks of shedding salmonellae and other potential pathogens by therapy dogs fed raw diets in Ontario and Alberta. Zoonoses Public Health. 2008;55(8-10):470-80.

30. Leonard EK. What could your dog be carrying? - Zoonotic enteric bacteria in pet dogs in Ontario: prevalence, risk factors, and antimicrobial resistance. Ontario: The University of Guelph; 2014.

31. Kim S, Kim S, Shin J, Lee B, Park M. Occurrence and distribution of various genetic structures of class 1 and class 2 integrons in salmonella enterica isolates from foodborne disease patients in Korea for 16 years. Foodborne Path Dis. 2010;8(2):319-24.

32. Public Health Surveillance Information for New Zealand Public Health Action, Human Salmonella Isolates. 2012. No.12 December. https://surv.esr cri.nz/enteric reference/human_salmonella.php?we_objectID=3266. Accessed 10 Apr 2017.

33. Münch S, Braun P, Wernery U, Kinne J, Pees M, Flieger A, Tietze E, Rabsch W. Prevalence, serovars, phage types, and antibiotic susceptibilities of 
Salmonella strains isolated from animals in the United Arab Emirates from 1996 to 2009. Trop Anim Health Prod. 2012;44:1725-38.

34. Saphara I, Wasserman M, Friedman S. A new Salmonella type: Salmonella Bronex. J Bacteriol. 1955:69:447.

35. Alemu S, Zewde BM. Prevalence and antimicrobial resistance profiles of salmonella enterica serovars isolated from slaughtered cattle in Bahir Dar, Ethiopia. Trop Anim Health Prod. 2012;44(3):595-600.

36. Eguale T, Gebreyes WA, Asrat D, Alemayehu H, Gunn JS, Engidawork E. Non-typhoidal salmonella serotypes, antimicrobial resistance and co-infection with parasites among patients with diarrhea and other gastrointestinal complaints in Addis Ababa, Ethiopia. BMC Infect Dis. 2015;15:497.

37. Tsai HJ, Huang HC, Lin CM, Lien YY, Chou CH. Salmonellae and campylobacters in household and stray dogs in northern Taiwan. Vet Res Commun. 2007;31(8):931-9.

38. Jajere SM, Onyilokwu SA, Adamu NB, Atsanda NN, Saidu AS, Adamu SG, Mustapha FB. Prevalence of salmonella infection in dogs in maiduguri, northeastern Nigeria. Int J Microbiol. 2014;2014:392548.

39. Beyene T, Endalamaw D, Tolossa Y, Feyisa A. Evaluation of rational use of veterinary drugs especially antimicrobials and anthelmintics in Bishoftu, Central Ethiopia. BMC Res Notes. 2015;8:482.

40. Kiflu B, Abdurahaman M, Alemayehu H, Eguale T. Investigation on public knowledge, attitude and practices related to pet management and zoonotic canine diseases in Addis Ababa, Ethiopia. Ethiopian Vet J. 2016;20(1):67-78.

41. Bedada A, Molla B. Tetracycline residue levels in slaughtered beef cattle from three slaughter houses in Central Ethiopia. Global Veterinaria. 2012;8(6):546-54.

42. Tadesse G, Gebremedhin EZ. Prevalence of salmonella in raw animal products in Ethiopia: a meta-analysis. BMC Res Notes. 2015;8:163.

\section{Submit your next manuscript to BioMed Central and we will help you at every step:}

- We accept pre-submission inquiries

- Our selector tool helps you to find the most relevant journal

- We provide round the clock customer support

- Convenient online submission

- Thorough peer review

- Inclusion in PubMed and all major indexing services

- Maximum visibility for your research

Submit your manuscript at www.biomedcentral.com/submit 